\title{
Landless female peasants living in resettlement residential areas in China have poorer quality of life than males: results from a household study in the Yangtze River Delta region
}

Ying Liang ${ }^{1 *}$ and Shuqin $\mathrm{Li}^{2}$

\begin{abstract}
Background: Urbanization has accelerated in China, and a large amount of arable land has been transformed into urban land. Moreover, the number of landless peasants has continually increased. Peasants lose not only their land, but also a series of rights and interests related with land. The problems of landless peasants have been long-standing; however, only a few studies have examined their health or quality of life (QOL). This paper assesses the QOL of landless peasants in the Yangtze River Delta (YRD) region, analyzes gender differences, and explores health inequity.

Methods: Data are derived from household samples in six resettlement residential areas of three cities (Nanjing, Hangzhou, and Yangzhou) in the YRD region ( $N=1,500$; the effective rate $=82.4 \%)$. This study uses the short version of World Health Organization Quality of Life questionnaire (WHOQOL-BREF) scale to measure the QOL of landless peasants, and performs confirmatory factor analysis (CFA) and analyze gender differences in QOL on the basis of CFA.

Results and conclusion: First, we use Analysis of Variance and Non-parametric Tests to test if the differences of mean value of testing generals have statistical significances. Results shows significant differences occur between the impacts of different genders on the four domains of QOL (physical health, psychological health, social relationships, and environment). The internal reliability of the WHOQOL-BREF scale is good (Cronbach's alpha $>0.8$ ), and the four domains of QOL are connected with each other. Second, scores in each QOL domain are commonly low, whereas the scores of females are much lower, indicating a poorer QOL than that of males. Third, results of the CFA of the QOL domains and their related observed variables indicate a good model fit. Fourth, results imply that the order of importance of the four domains (psychological health (males $=26.74 \%$, females $=27.17 \%$ ); social relationships ( males $=26.23 \%$, females $=25.35 \%$ ); environment (males $=25.70 \%$, females $=24.40 \%$ ); and physical health (males $=21.33 \%$, females $=23.08 \%$ ) ) affecting $\mathrm{QOL}$ from high to low is the same for landless male and female peasants, whereas the proportion of importance is different between genders. The results highlight the importance of government intervention to improve the QOL of Chinese landless peasants, ultimately reducing health inequity.
\end{abstract}

Keywords: Landless female peasants, QOL, WHOQOL-BREF, China, Yangtze river delta, CFA, Gender differences

\footnotetext{
*Correspondence: njulucy79@gmail.com

'Department of Social Work and Social Policy, School of Social and Behavioral Sciences, Nanjing University, Nanjing 210023, Jiangsu province, People's Republic of China

Full list of author information is available at the end of the article
} 


\section{Introduction}

Industrialization and urbanization have accelerated in China in recent years, and these trends have been accompanied by the increasing scale of arable land expropriated and the increasing number of landless peasants. The land of approximately 45 million peasants had been expropriated in rural China by 2007. Based on the growth rate and huge command of construction in the urbanization of China, the number of peasants whose land would be expropriated is predicted to increase to 42 million by 2020 , and the total number is expected to exceed 100 million by 2030 [1].

Landless peasants living in resettlement residential areas in China have been a long-standing problem. After the founding of the People's Republic of China in 1949, a large scale of land has been expropriated for the construction of a new city. However, arable land was collectively operated, and problems about landless peasants had not been seriously considered. After the implementation of the Reform and Opening-up Policy in 1978, the Household Responsibility System was launched in rural China, which allowed peasants to regain their land rights. The rapid development of urbanization resulted in the separate occurrence of two waves of Rodeo Heat in the mid-1980s and the early 1990s. Landless peasants were rehoused under the government plans, and they were offered jobs by companies that expropriated their lands based on the hiring index. The third Rodeo Heat with a larger scale occurred in 2000, in which urban and industrial areas expanded at an unprecedented rate. Moreover, infrastructure construction required additional land. An increasing amount of collective land in rural China are being occupied and transformed into urban land using all types of methods, Traditional peasants used to make a living on land; however, an increasing number of peasants are losing their land [2].

Related with this issue is the expression and protection issue of landless peasants' interests and demands. Influenced by the traditional ideology that Chinese people fear government officials and avoid political issues, the majority of landless peasants choose to remain silent about their interests. However, some individuals continue to choose to gather and initiate actions for their rights. For example, they express their problems to the upper government or turn to lawyers. The most extreme cases include certain individuals choosing to react uncompromisingly towards the situation by encouraging violent protests, demolition, some of which endanger the lives of many. These triggered aggressive events have evolved to be a major social concern. Examples are the reports of a female entrepreneur, Fuzhen Tang, in Chengdu City, Sichuan Province, who selfimmolated in 2009; the self-immolation of three villagers in Yihuang County, Jiangxi Province in 2010; and in 2014 when a fire broke out in the tents of peasants in Pingdu City, Shandong Province. The major news regarding landless peasants protesting against demolitions have shocked not only the country, but the entire world, which has resulted in far-reaching impact. In recent years, similar extreme events can be often seen in newspapers, serving as a reminder of the concerns of landless peasants and the sense of urgency in the situation.

Studies on Chinese landless peasants can be classified into two categories. The first category mostly focuses on how and why peasants lost their land. For instance, The urban land area in the Beijing-Tianjin-Hebei region expanded by $71 \%$ between 1990 and 2000. Approximately $74 \%$ of the new urban land was converted from arable land, and smaller cities tended to have higher percentages. One of the important reasons for this result is that urban land is highly correlated with arable land in spatial distribution [3]. Some scholars investigated farmland acquisitions and urban land transactions in Yingtan City in Jiangxi Province. They revealed that the current policy of increasing urban land conveyance through competitive mechanisms cannot help better protect the landless peasants [4]. Deng et al. reported that income growth plays a powerful role in the urban expansion of China, followed by population, value of agricultural land, transportation costs, industrialization, and the rise of the service sector; the last two factors affect the growth of the urban core [5].

The second category of studies examines how landless peasants live. In places where dynamic industries are lacking and lineage/kinship organizations are weak, the outcomes of property rights changes incurred by land requisition are often negative and even lethal to the livelihood of landless peasants. This case is particularly true in the less developed areas in inland China, especially the western region, an area that remains comparatively under investigated and less familiar to non-Chinese specialists. The imperfect implementation of compensation institutions (and possibly their imperfect design) implies that sums do not stack up for many dispossessed urban villages. These villages become vulnerable to poverty because they privately bear a significant proportion of the transaction costs of urban expansion [6]. Social concerns are absorbed into the issues of social tension and justice [7], social exclusion [8], social security of landless peasants $[9,10]$, and so on, all of which may pose a long-term threat to stability and sustainable development. Besides, urban integration and self-identity is one of the research directions of scholars, thought to be related to the temporality and spatiality transformation of landless peasants [11]. In general, the horizons of domestic research on the problem of landless peasants are relatively narrow because of the lack of comparative and systematic studies [2].

However, few studies focus on the health or quality of life (QOL) of Chinese landless peasants. QOL was developed 
by the World Health Organization (WHO). Certain scales have been widely used to measure the health-related quality of life (HRQOL) or QOL of China's overall population. The Chinese version of European Quality of Life (EQ-5D) has been used in nationwide or cities' investigations and has demonstrated acceptable construct validity and reliability [12-14]. The 36-item Short Form Health Survey (SF-36) is one of the popular scales. Many cities in China have applied the SF-36 scale. SF-12 is a short version of the SF-36 scale. The results can be considered reliable and sensitive in measuring the HRQOL of Chinese, while the SF-12 is an effective alternative of the SF-36.

The WHOQOL, an instrument for measuring QOL, assesses the perceptions of individuals regarding their position in life in the context of the culture and value systems in which they live and in relation to their goals, expectations, standards, and concerns. Because they refer to the international standards that are commonly used in the cross-cultural studies [15,16], the surveys help distinguish different vulnerable groups by epidemiological studies [17]. The WHOQOL Group first designed the WHOQOL-100 scale with 100 items, which consisted of 24 facets. Each facet has four questions. Moreover, four questions cover general QOL and health. The scale was aimed to measure people's QOL comprehensively. However, the WHOQOL-100 is lengthy and not suitable for the practical application. On the basic of WHOQOL-100 scale, WHOQOL-BREF is developed [18], which is composed of 26 items. Among them, two items measure the evaluation of general QOL and health. The 24 items can be divided into four domains. The measurement scores of two scales are substantially similar [19]. Therefore, the WHOQOL-BREF is a reliable and effective alternative of the WHOQOL-100 scale [20]. In consideration of reducing research costs or event rates that the hesitancy of respondents to finish the questionnaire because of the length, the majority of researchers choose the shorter version, the WHOQOLBREF scale.

In 1996, the WHOQOL-BREF scale was available in 19 different languages. Several countries proved the scale to be reliable and valid [21-25]. In 2004, the WHOQOL-BREF was available in 40 countries, translated in most languages [19]. One cross-cultural investigation indicated that WHOQOL-BREF was a sound and valid assessment of QOL [26]. The WHOQOL-100 and other shorter versions of the survey, particularly in the Chinese mainland, were translated by a research group from the School of Public Health, Sun Yat-sen University in 2000 [27]. They are also used in extensively measuring the QOL among Chinese, such as urban community residents [28], depressed older people [29], rural-to-urban migrants [30,31], patients with chronic diseases and their caregivers [32], and rural community residents after an earthquake [33].
Other methods are likewise used to measure the QOL of Chinese peasants; however, these methods mostly focus on specific groups, such as children living in HIV/ AIDS-affected families [34] and older populations [35]. Only a few studies focus on the QOL of Chinese landless peasants. The current study attempts to fill the gap in the literature using the WHOQOL-BREF to measure the QOL of Chinese landless peasants, and conducts a comparison between male and female peasants to determine health inequity among Chinese landless peasants.

As characteristics of a large vulnerable group, women's physical health is widely acknowledged to be in an unfavorable state. The reasons involved are diverse and complex, including social, political, cultural, and personal factors [36]. They can be divided into four facets: discriminatory values, norms within households and communities, differential exposures and vulnerability to diseases, biases in health system and biased health research [37]. Although feminism has progressed with advances in civilization and technology, some aspects have changed significantly. Reevaluating this view becomes necessary [38]. Still many studies that focused on the health of specific populations found that women's health was in disadvantaged conditions; the objects include earthquake survivors [39,40], different groups of patients $[41,42]$, and general population with different ages $[43,44]$. Gender inequity not only hurts the health of millions of women, but also brings indirect disadvantages to men, such as more risky and unhealthy behaviors [37]. For Chinese women living in rural areas, this situation is even more complicated. The rapid economic development with the country's participation in the globalization process has brought a double-edged effect on rural women's health. On one hand, eliminating absolute poverty helps reduce the prevalence rate of rural women; on the other hand, young men have left their homes to work in factories in cities, leaving their families behind. Many women had to shoulder several responsibilities such as attending to families, farming, and household chores. Even for women who left their homes to work, they are forced to overwork in order to earn a living. Therefore, in either circumstance, rural women are faced with severe physical, psychological, and social health crises [45]. As a result, combining the abovementioned concerns regarding the health of peasants, we considered the health of female landless peasants to be worthy of our study.

Early studies have indicated that China achieved significant progress in women's health in the 1950 to 1990 period; nevertheless, far less was achieved with respect to gender equality overall, and a disparity in health between men and women remained [46]. A survey conducted in the late 1990s in Hebei Province likewise cited gender differences in health, and age was related to the 
size of gender difference [47]. A study in 2008 reported that women were less likely to learn information about tuberculosis and share it with others on their own initiative, and a larger proportion of women preferred to initially visit the lower-level non-hospital health facilities, such as village clinics and drugstores [48]. QOL is closely related to health. Thus, we propose the first hypothesis in this study.

Hypothesis 1: Chinese landless female peasants have a lower QOL than their male counterparts.

In rural China, several social class indicators (i.e., education, income, and occupation) are associated with health [49]. In rural China, girls experience more difficulty in obtaining education compared to boys [50-53]. Moreover, education-related gender differences in health exist [54]. And eduction is a powerful indicator for health inequality in rural China [55]. Based on the foregoing analysis, we propose the second hypothesis in this study.

Hypothesis 2: Different domains of QOL demonstrate gender disparity among Chinese landless peasants.

Peasants' loss of land is an inevitable phenomenon in the development of society and urbanization. Peasants not only lose land and natural resources that they use to make a living, but also face an awkward situation in which they have no rights to share the achievements of urbanization because of institutional constraints. Finally, they are abandoned by urbanization and lose any livelihood security. Determining their QOL should be of social concern. This study uses the WHOQOL-BREF scale to measure the QOL of Chinese landless peasants, and analyzes gender differences. It aims to (1) assess the QOL of Chinese landless peasants and raise the social concern for these peasants; (2) explore health inequity among genders and promote special concern for Chinese landless female peasants; and (3) provide policy suggestions for government to improve health equality among landless rural peasants.

\section{Methods}

\section{Samples and sampling procedure}

The Yangtze River Delta (YRD) region is located in the fanshaped alluvial plain where the Yangtze River runs into the East China Sea. The YRD region comprises 30 cities led by Shanghai, and has acreage of 210,000 square meters and a population of 159 million. This region absorbs several types of industries, economies, trades, education, technologies, culture, and so on. It has been engineered to pull the economy of the Yangtze River basin, connecting domestic with foreign market, absorbing foreign investment, promoting industrial and technological transfer, and joining international competition and regional reconstruction. Rapid economic development is inevitably accompanied by the rapid expansion of urbanization.
First, we used a non-random (non-probability) sampling method in selecting three cities (Yangzhou City in Jiangsu Province, Nanjing City in Jiangsu Province, and Hangzhou City in Zhejiang Province) in 30 cities of the YRD region (Figure 1). These three cities were selected because they had a GDP growth rate of approximately $10 \%$ in 2012, indicating their rapid development [56]. According to the 2012 annual data of local Bureaus of Statistics, the proportions of urban population of Nanjing and Yangzhou cities are higher than that those of rural population. And Hangzhou City has more rural populations. Samples taken in these three cities not only contribute a high quality of representativeness, but also produce certain reference values on how to improve the QOL of landless peasants with a larger scale in China.

Second, according to the information provided by the local Ministry of Civil Affairs, landless peasants can obtain a certain amount of money as compensation for the loss of their land; meanwhile, arrangements to move to a community are made for the landless peasants. We used a random (probability) sampling method in selecting the resettlement residential areas; two were chosen from all communities that are built to settle landless peasants in each city (two communities in Hanjiang District, Yangzhou City; two communities in Jiangning District, Nanjing City; two communities in Xihu District, Hangzhou City), as illustrated in Figure 1.

Interviewers with professional training skills administered household surveys to landless peasants living in these communities. Households were stratified by the number of adults in the household, and a Kish grid sampling method was used to perform equal probability sampling within each stratum. The results of a health survey in China indicated that the demographic characteristics of age and gender of the Kish grid sample approximated to the population, suggesting that the Kish grid is a sampling method that is practicable and easy to monitor. Moreover, this method can effectively decrease the bias derived from the sampling procedure within households [57]. Each questionnaire was independently completed by a respondent under the instructions of the interviewer. Up to 1,500 questionnaires were distributed, or 500 questionnaires in each city. We collected 1,236 valid questionnaires, and derived an effective collection rate of $82.4 \%$.

The current study principally measured the QOL of landless peasants in the YRD region using the WHOQOL-BREF scale. The WHOQOL-BREF contains four domains, namely, physical health, psychological health, social relationships and environment. These domains have 26 items. Three of these items are reverse-scored and two are overall questions that yield information on global QOL and health. The reverse items are converted according to the method shown in the WHOQOL instructions. The four domains have the following number of items: seven (Q3, Q4, Q10, Q15, Q16, Q17, Q18), six (Q5, Q6, Q7, Q11, Q19, Q26), three (Q20, Q21, Q22), and eight 


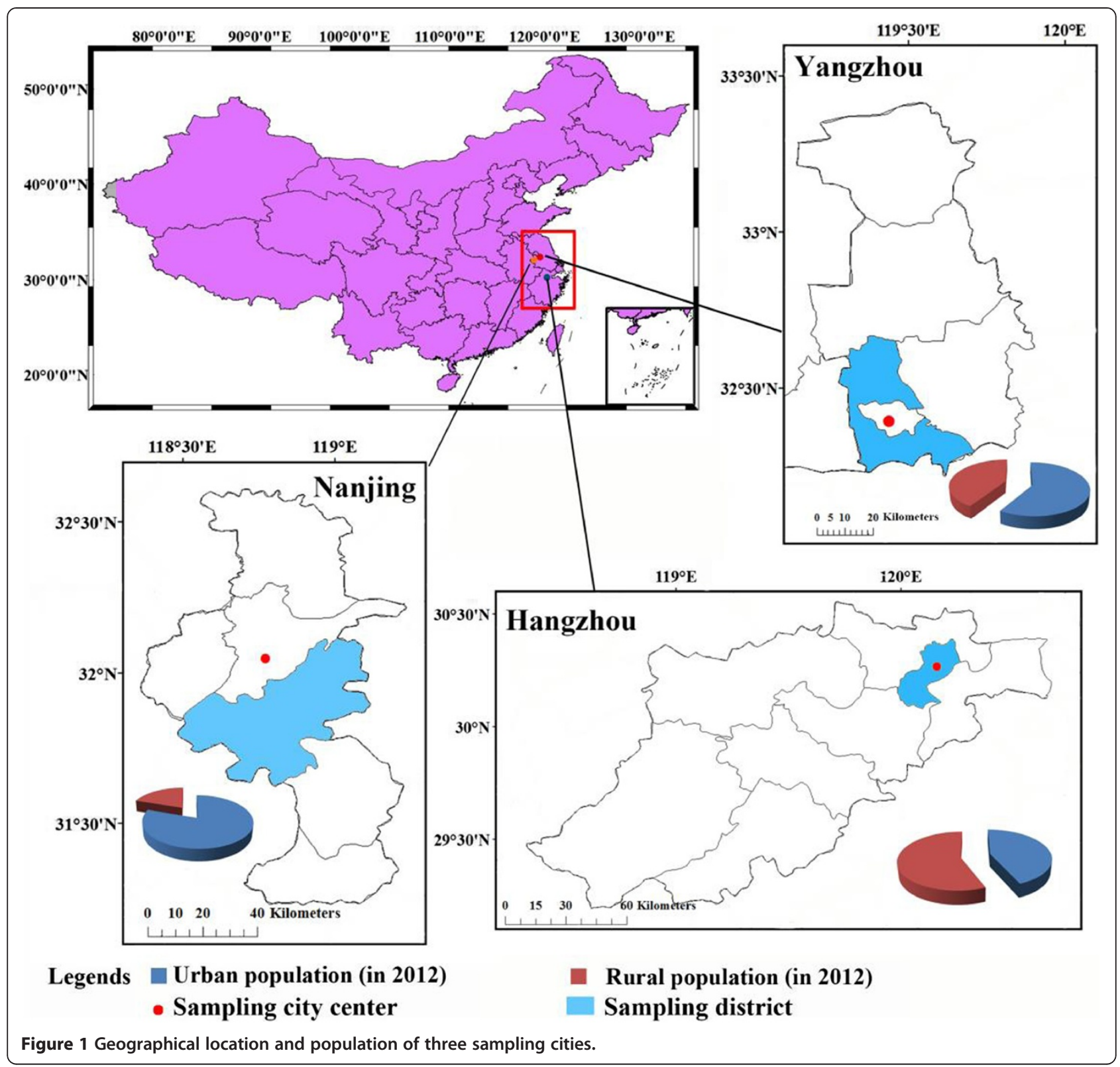

(Q8, Q9, Q12, Q13, Q14, Q23, Q24, Q25), respectively. We normalize the obtained data (Formula 1) to facilitate the comparison of all domains. Final scores are in the range of 0 and 100. Higher scores indicate that the respondents have a higher QOL.

Formula 1:

$$
\text { Converted scores }=(\text { Raw scores }-4) *(100 / 16)
$$

As compared with the SF-36 scale, another international popular scale with strong reliability and validity, the WHOQOL-BREF has fewer ceiling effects [58]. The SF-36 measures the HRQOL instead of the global QOL [59]. Table 1 shows a detailed comparison of Spearman correlation coefficients between two scales. In general, the correlation coefficients of each domain of two scales are relatively high. For example, the correlation coefficients between four domains of WHOQOL-BREF and physical functioning (PF) are all above 0.730 , indicating high correlations. The correlations between four domains of WHOQOL-BREF and role physical (RP) are strong; their coefficients are all above 0.640. Generally, if the domains of two scales have overlapping portions, the correlations are strong; if the domain of one scale is not mentioned in another scale, the correlation is weak. For example, the correlation coefficient of each domain of WHOQOL-BREF and Vitality (VT) of SF-36 scale are approximately 0.1 , which is relatively low. In summary, the analysis results of scales indicate strong reference values. 
Table 1 Comparison of the correlations coefficients between two scales

\begin{tabular}{lcccccccc}
\hline Physical health & 0.784 & 0.694 & 0.658 & 0.195 & 0.109 & 0.268 & 0.667 & 0.402 \\
Social relationships & 0.790 & 0.680 & 0.648 & 0.204 & 0.088 & 0.282 & 0.674 & 0.390 \\
Social relationships & 0.738 & 0.643 & 0.615 & 0.219 & 0.100 & 0.251 & 0.645 & 0.356 \\
Environment & 0.797 & 0.679 & 0.653 & 0.194 & 0.107 & 0.269 & 0.689 & 0.405 \\
& PF & RP & BP & GH & VT & SF & RE & MH \\
\hline
\end{tabular}

Note: In the eight domains of SF-36 scale, PF: Physical functioning; RP: Role physical; BP: Bodily pain; GH: General health; VT: Vitality; SF: Social functioning; RE: Role emotional; MH: Mental health.

Figure 2 illustrates the difference of proportion of score between SF-36 and WHOQOL-BREF. The ranges of transferred scores of two scales are 0 to 100 . Recoding the scores can be transferred into ten levels from 1 to 10 as illustrated in the horizontal axis and the vertical axis indicates the population percentage in this score. The higher the bar graph is, the more people scored HRQOL in this level. As illustrated in Figure 2, the number of people who scored in the highest or lowest level is minimal, compared to the people who scored in the middle level. Comparison indicates subtle differences in the levels between two scales. One example is the number of people who scored the fifth level in SF-36 scale peaks, whereas that of WHOQOL-BREF does not have any apparent peaks. The bars in No. 3, 5, 8 of WHOQOLBREF scores are balanced, indicating high proportions.

\section{Analysis methods \\ Reliability analysis}

The reliability and validity of questionnaires are tested after their completion. Reliability test has nothing to do with the correctness of the measurement results obtained; instead, it examines whether or not the measurement itself is stable. The most commonly used method is Cronbach's $\alpha$ coefficient, which principally tests the internal reliability of the scale and determines any internal consistency among items in the scale. This coefficient is always believed to be between 0 and 1 . A value larger than 0.9 indicates that the reliability test result is very good; a value between 0.8 and 0.9 indicates that the reliability test result is acceptable; a value between 0.7 and 0.8 indicates that some items in the scale need to be revised; and a value less than 0.7 indicates that some items in the scale need to be moved. Reliability analysis can help judge the stability and reliability of a scale.

\section{Analysis of variance}

Analysis of variance (ANOVA) is a method to determine whether the difference of a mean value of two or more of generals have statistical significances. To increase the effectiveness of ANOVA, we hypothesized that the compared generals have the same variances. The difference of health between male and female landless peasants will be studied. Thus, the homogeneity of variance tests will be conducted first, then the ANOVA.

\section{Nonparametric tests}

ANOVA needs to make hypotheses on the nature of general samples; that is, to introduce certain limitations to the distribution shape of generals. When the variances of one domain of male and female generals are not equal, ANOVA is therefore not appropriate. The non-parametric tests do not involve the general parameters. As such, the test conditions are lenient and adaptable. Moreover, the method is more flexible and versatile. The specific nonparametric test used in this study is the Mann-Whitney U test. The test is conducted by studying the average rank of two groups of samples. The original hypothesis is that no significant differences occur on the distribution of generals between two groups of independent samples.

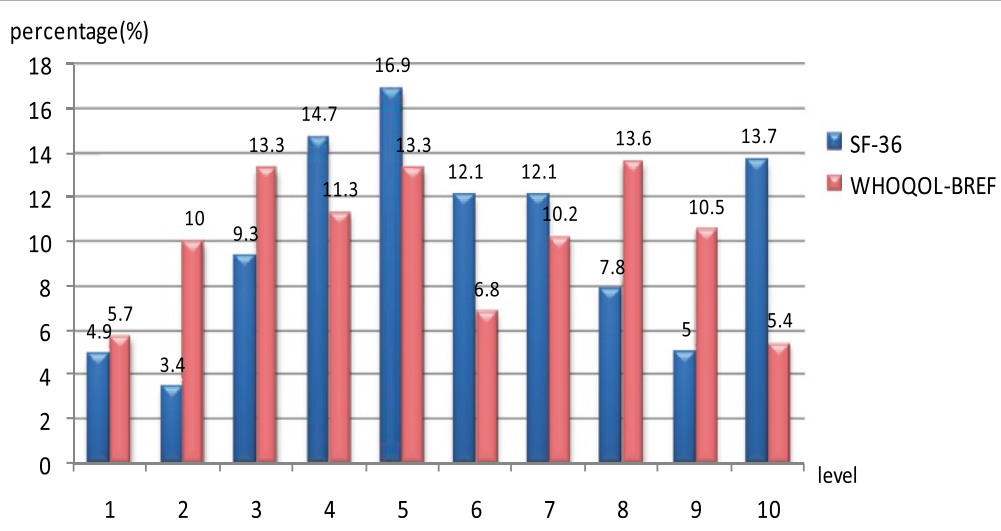

Figure 2 Comparison of SF-36 and WHOQOL-BREF scores. 


\section{Confirmatory factor analysis}

A confirmatory factor analysis (CFA) model determines the true population variance, covariance, estimated population variance, sample covariance, and estimated covariance, as well as the related overall difference and the approximated, estimated, and sample differences. Goodness of fit is an indicator for testing the similarity between the model-estimated covariance matrix and sample covariance. Chi square to degree of freedom ratio $\left(\chi^{2} / \mathrm{df}\right)$ is an indicator for testing the similarity between the sample covariance matrix and the estimated covariance matrix, and its theoretical expected value is 1 . If $\chi^{2} / \mathrm{df}$ is closer to 1 , then the sample covariance matrix and estimated covariance matrix are more similar. In a practical study, when $\chi^{2} / \mathrm{df}$ is closer to 2 , the model demonstrates better fit. When the scale of a sample is large, then the value of $\chi^{2} / \mathrm{df}$ approximately 5 is acceptable.

\section{Gender differences analysis based on CFA}

Confirmatory factor analysis (CFA) is a special application of structural equation modeling (SEM) analysis. It is a factors analysis procedure that explores whether the factor structure of the scale model is collected fit the actual data, whether the index of scalar can be effectively used as a factor dimensions (latent variable) measuring variables. In this study, we use second-order confirmatory factor analysis in structural equation modeling to test the appropriateness and authenticity of the established factors structural models. Besides, we explore the path coefficients of female and male's various domains which affect the quality of life. Through the processing of the WHOQOL-BREF scale data, we calculate male and female's composite scores in four domains, build mutual relations in various domains. Thus, form the corresponding theoretical assumptions, and the path coefficients to estimate the theoretical model.

\section{Ethical statement}

Research involving human subjects (including human material or human data) in this study has been performed with the approval of ethnics committee of the School of Social and Behavioral Sciences, Nanjing University. Research carries out on humans has been in compliance with the Helsinki Declaration. And the authors would take the interpretation and responsibility for results involving human subjects in this study.

\section{Consent statement}

Before respondents filled in the questionnaire in this study, they had been told that their data would be used only for academic research, and they ensured that their information filled in the questionnaire was in accordance with the actual situation. Where participants are children, their parent or guardian was consent for the participation.

\section{Results}

\section{Descriptive statistics}

Table 2 shows the results of the comparative analysis of the descriptive statistics in the four domains of the WHOQOL-BREF scale $(\mathrm{N}=1236)$. Specifically shown from top to bottom are the mean values, median values, plural values, variance, skewness, kurtosis, full distance, minimum values, and maximum values.

The results indicated unsatisfactory scores in the four domains of WHOQOL-BREF among landless peasants. Under the 100-score scale, the highest mean value was 50.7723 in the domain of social relationships, and the other three domains all obtained scores lower than 50. Four domains exhibited a impact on the QOL of landless peasants.

In the plural value statistics, most of the respondents obtained scores of 32.14 in physical health and 29.17 in psychological health; meanwhile, scores in social relationships and environment were higher than the former two. In the variance statistics, the score in social relationships was the highest at 807.939 , which indicated a difference with the other three domains. In other words, data in these three domains were more stable than those in social relationships. In the kurtosis statistics, scores in the four domains were all less than 0 , which indicated that data distribution was not as steep as the standard normal distribution, but was slightly smooth. Moreover, no great differences were found in the full distance, minimum value, and maximum value statistics among the four domains.

Comparison of data showed that landless peasants obtained the lowest mean scores in physical health (46.3169), and a median value of 46.4300 , with a slight difference with the mean value. The value of variance in physical health was the lowest among four domains, indicating that landless peasants obtained a relatively concentrated score of 46 , with less volatile data and a smaller difference in scores. In social relationships, the mean value was 50.7723 , median value was 50.0000 , and variance obtained the largest value, indicating that data in this domain exhibited a difference. In other words, landless peasants demonstrated the lowest consistency when assessing their attitude in this domain.

\section{Homogeneity of variances}

As can be seen in Table 3, only the $P$-values of probability, which are above 0.05 , correspond to physical health and social relationships. Thus, the variances of physical health and social relationships under different genders are the same and will satisfy the prerequisites of ANOVA. The $P$-value of another two variables show to be less than the significance level, which means the variances of different genders are not the same. Accordingly, the ANOVA cannot be adopted. We used One-way ANOVA to analyze whether gender has significant differences in terms of physical health and social relationships, and used Mann-Whitney U nonparametric test to 
Table 2 Descriptive statistics of the WHOQOL-BREF scale

\begin{tabular}{|c|c|c|c|c|}
\hline & Physical health & Psychological health & Social relationships & Environment \\
\hline \multirow{2}{*}{ N } & 1236 & 1236 & 1236 & 1236 \\
\hline & 0 & 0 & 0 & 0 \\
\hline Mean value & 46.3169 & 47.2594 & 50.7723 & 47.6517 \\
\hline Median value & 46.4300 & 41.6700 & 50.0000 & 43.7500 \\
\hline Plural value & 32.14 & 29.17 & 83.33 & 78.13 \\
\hline Variance & 591.825 & 681.694 & 807.939 & 639.800 \\
\hline Skewness & .091 & .258 & -.033 & .109 \\
\hline Standard error of skewness & .070 & .070 & .070 & .070 \\
\hline Kurtosis & -1.129 & -1.252 & -1.238 & -1.242 \\
\hline Standard error of kurtosis & .139 & .139 & .139 & .139 \\
\hline Full distance & 100.00 & 95.83 & 100.00 & 96.88 \\
\hline Minimum value & .00 & 4.17 & .00 & .00 \\
\hline Maximum value & 100.00 & 100.00 & 100.00 & 96.88 \\
\hline
\end{tabular}

study whether gender has significant differences with the remaining variables Table 4 shows the results of physical health and social relationships for ANOVA.

The sum of squared variations of physical health is 620243.367. If only one factor (gender) is considered, among the total variation of physical health, the interpretable variation of different gender is 209854.972; the variation caused by sampling errors is 410388.395 . Their variances are 209854.972 and 209854.972, respectively. The F-statistic result acquired by division is 568.118 . The corresponding $\mathrm{P}$-value is approximately 0 . If the significance level $(\alpha)$ is 0.05 , because the $P$-value is less than $\alpha$, the original hypothesis is rejected. Hence, significant differences occur between the impacts of different genders on physical health.

The sum of squared variation of social relationships is 948170.290. If only one factor (gender) is considered, among the total variation of social relationships, the interpretable variation of different gender is 244473.315; the variation caused by sampling errors is 703696.975 . Their variances are 244473.315 and 612.976 , respectively. The $F$-statistic result acquired through the division is 398.830. The corresponding $\mathrm{P}$-value is approximately 0 . Because the $P$-value is less than $\alpha$, the original hypothesis is rejected. Hence, significant differences occur between the impacts of different genders on social relationships.

Table 3 Test results for homogeneity of variances

\begin{tabular}{lcccc}
\hline & Levene statistic & df1 & df2 & Sig. \\
\hline Physical health & 1.577 & 1 & 1111 & .209 \\
Psychological health & 34.126 & 1 & 1073 & .000 \\
Social relationships & 1.076 & 1 & 1148 & .300 \\
Environment & 6.991 & 1 & 1084 & .008 \\
\hline
\end{tabular}

\section{Nonparametric tests}

As demonstrated by the Mann-Whitney $U$ nonparametric test result in Table 5, the differences of the psychological health and environment under different genders are significant. Combining the results of ANOVA in Table 4, the differences of the four domains of WHOQOL-BREF under different genders are significant.

\section{Reliability analysis}

In Table 6, the Cronbach's $\alpha$ coefficients (third column) in the four domains of the WHOQOL-BREF scale are considerably larger than 0.800 , indicating that each item in the scale shows high internal consistency and good reliability. Meanwhile, the overall Cronbach's $\alpha$ coefficient is 0.926 , and becomes 0.928 after being standardized. Reliability coefficient is larger than 0.8 , indicating good internal reliability and high internal consistency of the scale. In other words, this scale has high value.

Moreover, if the items are removed, the Cronbach's $\alpha$ coefficient of each domain is less than the overall one, 0.926. When the physical health, psychological health, social relationships, and environment are separately removed, the Cronbach's a coefficients are 0.909, 0.893, 0.922 , and 0.892 , respectively. If the items are removed, all Cronbach's $\alpha$ coefficients are less than the overall coefficient of 0.926 , which indicates that the separate removal of any domain is meaningless. These four domains are closely connected with each other.

Scores in the WHOQOL-BREF scale are positive values; a higher score indicates a better QOL. Table 7 shows the gender difference in the scores of four domains of Chinese landless peasants. Under the 100 -score scale, landless peasants commonly obtain low scores in each QOL domain, whereas males obtain higher scores than females. Compared with males, females obtain lower scores of 27.64 in 
Table 4 Results for ANOVA

\begin{tabular}{llcccc}
\hline & & Sum of squares & df & Mean square & F \\
\hline \multirow{3}{*}{ Physical health } & Between Groups & 209854.972 & 1 & 209854.972 & 568.118 \\
& Within Groups & 410388.395 & 1111 & 209854.972 & .000 \\
Social relationships & Total & 620243.367 & 1112 & & \\
& Between Groups & 244473.315 & 1 & 244473.315 & 398.830 \\
& Within Groups & 703696.975 & 1148 & 612.976 & .000 \\
& Total & 948170.290 & 1149 & & \\
\hline
\end{tabular}

psychological health, 30.51 in physical health, 28.84 in social relationships, and 28.69 in environment. Males obtain much higher scores of nearly 30 than females in each domain, indicating a great gender difference in the QOL.

When all landless peasants demonstrate low scores in the QOL, males obtain higher scores than females, indicating a considerable gender difference in each QOL domain. Females obtain lower scores of variance in the four domains than males, indicating a lower difference in the scores of four domains. In others words, the degree of concentrated scores in each domain is higher among females than males. Meanwhile, females obtain lower mean values than males, indicating that females obtain lower scores in each domain. Thus, gender difference affects the QOL among Chinese landless peasants.

As indicated in Figure 3, the mean value is small, indicating that landless female peasants are disadvantaged in the four domains of QOL. And the variance of males is greater than that of females, indicating that the fluctuation of men's scores are greater than that of women's scores.

\section{CFA model}

Figure 4 shows the CFA model for the WHOQOL-BREF scale. In this model, the QOL is a latent variable, and its indicators consist of four domains that are connected by a single-direction arrow. Moreover, the fitting indices for comparing the CFA model with the reference standard are the root mean residual (RMR), the root mean square error of approximation (RMSEA), goodness of fit index (GFI), adjusted goodness of fit Index (AGFI), normed fit Index (NFI), incremental fit index (IFI), Tucker-Lewis Index((TLI) non-normed fit Index (NNFI), comparative

Table 5 Result of Mann-Whitney U nonparametric tests

\begin{tabular}{lcc}
\hline & Psychological health & Environment \\
\hline Mann-Whitney U & 49166.500 & 52655.500 \\
Wilcoxon W & 170937.500 & 168576.500 \\
Z & -18.615 & -18.098 \\
Asym.Sig & .000 & .000 \\
\hline
\end{tabular}

fit index (CFI), parsimonious GFI (PGFI), parsimonious NFI (PNFI), parsimonious CFI (PCFI).

Table 8 shows the CFA analysis results of the WHOQOL-BREF scale, including parameter estimation, CR coefficient, accompanied probability between four domains and QOL, as well as between certain items and their related domains. According to the results of the former four columns, the parameter estimation values are all larger than 1 , indicating that the related domains can reflect the QOL of the measure group. The CR coefficients are all larger than 2, indicating that most accompanied probabilities passed the significance tests, and they demonstrate good analysis results. Factor analysis results between certain items and their related domains exhibit a relatively large value of parameter estimation (only one is less than 0.80 , and others are larger than 0.80 ). Most CR coefficients are larger than 18, indicating the high validity of the scale. Analysis results indicate significant implications for the QOL among landless female peasants in living in the resettlement residential areas in China.

First, psychological health shows the greatest impact on the QOL of landless peasants, with a coefficient of 1.154. The lack of concern for psychological health has negatively affected the QOL of landless peasants. In rural China, peasants care little about their psychological health and typically ignore problems related to their psychological wellbeing. These behaviors decrease their QOL. Thus, examining the QOL among landless female peasants is practical and valuable.

Second, the domain of social relationships shows the second greatest impact on the QOL of landless peasants, with a coefficient of 1.144. This result is understandable. When their land is expropriated, peasants lose their means of livelihood and experience changes in their social relationships, thereby significantly affecting their QOL. If their social relationships are unsatisfactory and the necessary social support is missing, their QOL will decrease. Thus, a discussion on solving strategies should raise awareness of the contribution of the loss of land to the lack of a social support system. Women are more likely to have weak social relationships because of their more disadvantaged social status. The loss of land connotes the loss not only of a source of livelihood, but also 
Table 6 Reliability test

\begin{tabular}{lcc}
\hline Domains & $\begin{array}{c}\text { Number of } \\
\text { observed variables }\end{array}$ & $\begin{array}{c}\text { Cronbach's a coefficient if } \\
\text { the items are removed }\end{array}$ \\
\hline Physical health & 7 & 0.909 \\
Psychological health & 6 & 0.893 \\
Social relationships & 3 & 0.922 \\
Environment & 8 & 0.892 \\
\hline
\end{tabular}

of normal social relationships. The domain of social relationships should be considered in undertaking efforts to improve the QOL of landless female peasants.

Third, physical health shows a relatively weak impact on the QOL of landless peasants. Physical pain and exhaustion may not be the principal QOL factors, and physical health does not directly affect their lives. Moreover, physical health may show a long-term slow impact on QOL. Thus, its parameter estimation value is relatively lower than the other domains.

Four, the domain of environment shows the third greatest impact on the QOL of landless peasants, with a coefficient of 1.120. This result is reasonable. When they become landless peasants, their living environments change, both social and natural, hence significantly affects their QOL.

Table 9 shows the fitting indices to the second-order CFA model of the WHOQOL-BREF scale. The first column shows the fitting indices, the second column shows the reference standards for the model, the third column shows the testing results of the model, and the fourth column shows whether or not the testing results for the model are appropriate. In Table 9, most fitting indices to the model reach an acceptable standard, indicating that the model fits well, and its external quality and convergent validity are good. Meanwhile, $\chi^{2}$ is $748.078, \mathrm{df}$ is 248 , and $\chi^{2} / \mathrm{df}$ is 3.016 , indicating that the overall model fits well and is acceptable.

\section{Gender differences analysis based on CFA}

Confirmatory factor analysis (CFA) is actually a special application of structure equation modeling (SEM) analysis. On the analysis of the above, second-order confirmatory factor analysis is used in structural equation modeling analyzing the appropriateness and authenticity of the established factors structural models. What's more, based on the above analysis, we explore the path coefficients of female and male's various domains which affect the quality of life. For each observed variable, data are distributed with normality, which meet the requirements of the model. A review of the previous literature and preprocessing of WHOQOL-BREF data allow the composite scores of four domains to be calculated, the correlations among domains to be established, the theoretical hypotheses to be tested, and the path coefficients of the theoretical model to be estimated. The estimated results are shown as follows.

$$
\begin{aligned}
\mathrm{QOL}(\text { male })= & 1.000 \times \text { Physical health }+1.254 \\
& \times \text { Psychological health }+1.230 \\
& \times \text { Social relationships }+1.205 \\
& \times \text { Environment }
\end{aligned}
$$

From Equation 1, when other domains remain unchanged, scores in physical health increase with 1 , and the QOL of males increases with 1; when scores in psychological health increase with 1, the QOL of males increases with 1.254; scores in the domain of social relationships increase with 1 , the QOL of males increases with 1.230; and when scores in the environment domain increase with 1 , the QOL of males increases with 1.205. Psychological health shows the greatest impact on the QOL of landless male peasants, followed by social relationships, environment, and physical health.

$$
\begin{aligned}
\mathrm{QOL}(\text { female })= & 1.000 \times \text { Physical health } \\
& +1.177 \\
& \times \text { Psychological health } \\
& +1.098 \times \text { Social relationships } \\
& +1.057 \times \text { Environment }
\end{aligned}
$$

Similar to Equation 1, in analyzing Equation 2, under the situation that other domains remain unchanged, scores in physical health increase with 1 , and the QOL of females increases with 1 ; when scores in psychological health increase with 1 , the QOL of females increases with 1.177; scores in the domain of social relationships increase with 1, the QOL of females increases with 1.098; and when scores in the environment domain increase with 1, the QOL of females increases with 1.057. Psychological health shows the greatest impact on the QOL of landless female peasants, followed by social relationships, environment, and physical health.

Table 7 Gender difference in the QOL of Chinese landless peasants

\begin{tabular}{lcccc}
\hline Domains & Mean value (male) & Mean value (female) & Variance (male) & Variance (female) \\
\hline Psychological health & 59.90 & 32.26 & 20.96 & 19.05 \\
Physical health & 62.18 & 31.67 & 23.36 & 18.76 \\
Social relationships & 64.97 & 36.13 & 25.39 & 23.49 \\
Environment & 61.71 & 33.02 & 21.98 & 19.40 \\
\hline
\end{tabular}




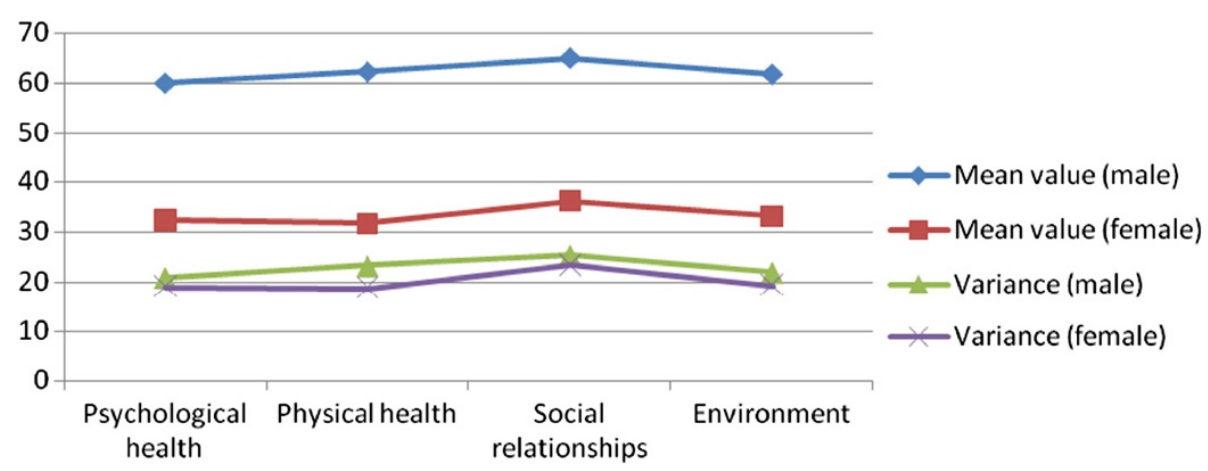

Figure 3 Comparison of the four domains of QOL under gender differences.

In the comparison of data from Tables 10 and 11, each domain shows a positive correlation with the QOL of landless male and female peasants. However, when scores in each domain increase with 1 , the QOL increases more substantially among males than females. In other words, when psychological health, social relationships, environment, and physical health improve, the QOL of males improves more considerably than that of females. If females desire a similar improvement in their
QOL, they have to make more positive changes in psychological health, social relationships, environment, and physical health. They will experience more difficulties in attempting to improve their QOL. Thus, the QOL of females should be given more attention.

The key findings in Table 12 are as follows.

First, differences in paths coefficients are shown on the QOL of both males and females. For males, psychological health shows the greatest impact on the QOL, with a

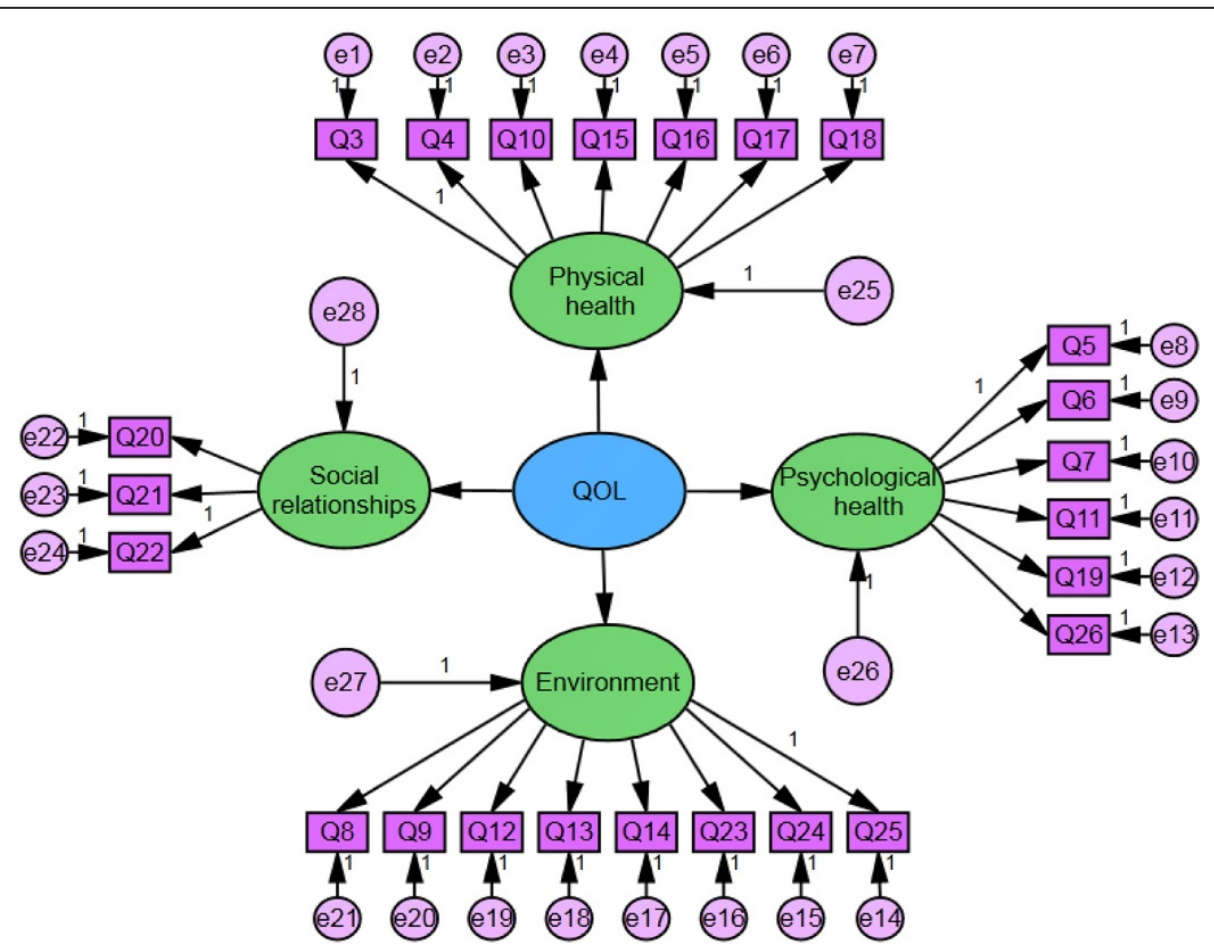

Figure 4 CFA model of the WHOQOL-BREF scale for the female landless peasants. Note: Q3-Q26Indicate the 24 items of WHQOL-BREF scale. Q3: Pain and discomfort; Q4: Dependence on medicinal substances and medical aids; Q5: Positive feelings; Q6: Spirituality / Religion / Personal beliefs; Q7: Thinking, learning, memory and concentration; Q8: Freedom, physical safety and security; Q9: Physical environment (pollution / noise / traffic / climate); Q10: Energy and fatigue; Q11: Bodily image and appearance; Q12: Financial resources; Q13: Opportunities for acquiring new information and skills; Q14: Participation in and opportunities for recreation / leisure activities; Q15: Mobility; Q16: Sleep and rest; Q17: Activities of daily living; Q18: Work Capacity; Q19: Self-esteem; Q20: Personal relationships; Q21: Sexual activity; Q22: Social support; Q23: Home environment; Q24: Health and social care: accessibility and quality; Q25: Transport; Q26: Negative feelings. 
Table 8 CFA analysis of the WHOQOL-BREF scale

\begin{tabular}{|c|c|c|c|c|c|c|}
\hline & & & Estimate & S.E. & C.R. & $P$ \\
\hline Physical health & $<---$ & $\mathrm{QOL}$ & 1.000 & & & \\
\hline Social relationships & $<---$ & $\mathrm{QOL}$ & 1.144 & .058 & 19.660 & *** \\
\hline Psychological health & $<---$ & $\mathrm{QOL}$ & 1.154 & .057 & 20.108 & $* * *$ \\
\hline Environment & $<--$ & $\mathrm{QOL}$ & 1.120 & .058 & 19.416 & $* * *$ \\
\hline Q16 & $<--$ & Physical health & 1.000 & & & \\
\hline Q15 & $<--$ & Physical health & 1.028 & .057 & 18.087 & *** \\
\hline Q10 & $<---$ & Physical health & 1.026 & .057 & 18.001 & *** \\
\hline Q4 & $<---$ & Physical health & .823 & .055 & 15.038 & *** \\
\hline Q3 & $<---$ & Physical health & 1.042 & .057 & 18.324 & *** \\
\hline Q18 & $<---$ & Physical health & 1.142 & .058 & 19.632 & *** \\
\hline Q17 & $<---$ & Physical health & .981 & .057 & 17.121 & *** \\
\hline Q22 & $<---$ & Social relationships & 1.000 & & & \\
\hline Q21 & $<--$ & Social relationships & .911 & .041 & 22.174 & *** \\
\hline Q20 & $<---$ & Social relationships & 1.080 & .044 & 24.763 & $* * *$ \\
\hline Q5 & $<---$ & Psychological health & 1.000 & & & \\
\hline Q6 & $<---$ & Psychological health & .844 & .044 & 19.352 & *** \\
\hline Q7 & $<---$ & Psychological health & 1.018 & .044 & 22.888 & *** \\
\hline Q11 & $<---$ & Psychological health & .747 & .040 & 18.514 & $* * *$ \\
\hline Q19 & $<---$ & Psychological health & .909 & .044 & 20.868 & *** \\
\hline Q26 & $<---$ & Psychological health & .980 & .041 & 23.978 & $* * *$ \\
\hline Q8 & $<---$ & Environment & 1.000 & & & \\
\hline Q9 & $<---$ & Environment & .934 & .047 & 19.925 & $* * *$ \\
\hline Q12 & $<---$ & Environment & .944 & .048 & 19.701 & *** \\
\hline Q13 & $<--$ & Environment & .938 & .049 & 19.239 & $* * *$ \\
\hline Q14 & $<---$ & Environment & .833 & .046 & 18.275 & $* * *$ \\
\hline Q23 & $<---$ & Environment & 1.118 & .048 & 23.448 & *** \\
\hline Q24 & $<---$ & Environment & 1.088 & .049 & 22.332 & $* * *$ \\
\hline Q25 & $<--$ & Environment & .899 & .044 & 20.459 & *** \\
\hline
\end{tabular}

Note: ***indicates the path coefficients are significant when their confidence interval is over 99\%. Q3-Q26Indicate the 24 items of WHQOL-BREF scale. Q3: Pain and discomfort; Q4: Dependence on medicinal substances and medical aids; Q5: Positive feelings; Q6: Spirituality / Religion / Personal beliefs; Q7: Thinking, learning, memory and concentration; Q8: Freedom, physical safety and security; Q9: Physical environment (pollution / noise / traffic / climate); Q10: Energy and fatigue; Q11: Bodily image and appearance; Q12: Financial resources; Q13: Opportunities for acquiring new information and skills; Q14: Participation in and opportunities for recreation / leisure activities; Q15: Mobility; Q16: Sleep and rest; Q17: Activities of daily living; Q18: Work Capacity; Q19: Self-esteem; Q20: Personal relationships; Q21: Sexual activity; Q22: Social support; Q23: Home environment; Q24: Health and social care: accessibility and quality; Q25: Transport; Q26: Negative feelings.

proportion of path coefficients of $26.74 \%$, followed by social relationships (26.23\%) and environment (25.70\%); physical health shows the least impact with a proportion of $21.33 \%$. For females, psychological health shows the greatest impact on QOL, with a proportion of path coefficients of $27.17 \%$, followed by social relationships $(25.35 \%)$ and environment (24.40\%); physical health shows the least impact with a proportion of $23.08 \%$.

Second, the importance of the four domains affecting QOL is the same for landless male and female peasants. The proportion of path coefficients signifies that psychological health shows the greatest impact on the QOL of males $(26.74 \%)$ and females $(27.17 \%)$. The domain of social relationships shows the second greatest impact on the QOL of males (26.23\%) and females (25.35\%), followed by environment (25.70\% for males, $24.4 \%$ for females) and physical health (21.33\% for males, $23.08 \%$ for females).

Third, the proportions of the four domains are different. The gap between the maximum and minimum proportions is $5.41 \%$ for males and $4.09 \%$ for females. Thus, the four domains demonstrate an average impact on the QOL of females, indicating their importance.

\section{Discussion}

The rapid development of urbanization in China has caused a larger number of peasants to lose their lands, with no rights to share the achievements of urbanization because 
Table 9 Fitting indices to the second-order CFA of the WHOQOL-BREF scale

\begin{tabular}{cccc}
\hline Fitting indices & Testing results & Testing results & Fitness \\
\hline $\boldsymbol{X}^{2}$ & & 748.078 & Yes \\
$\boldsymbol{X}^{2} / \boldsymbol{d f}$ & & 3.016 & Yes \\
RMR & $<0.05$ & 0.0301 & Yes \\
RMSEA & $0.08(<0.05:$ excellent; & 0.040 & Yes \\
& $<0.08:$ good $)$ & & \\
GFI & $>0.90$ & 0.944 & Yes \\
AGFI & $>0.90$ & 0.932 & Yes \\
NFI & $>0.90$ & 0.940 & Yes \\
IFI & $>0.90$ & 0.959 & Yes \\
TLI(NNFI) & $>0.90$ & 0.955 & Yes \\
CFI & $>0.90$ & 0.959 & Yes \\
PGFI & $>0.50$ & 0.780 & Yes \\
PNFI & $>0.50$ & 0.845 & Yes \\
PCFI & $>0.50$ & 0.862 & Yes \\
\hline
\end{tabular}

of institutional constraints. In the process of land acquisition with great interests, these peasants are often in a passive and weak position, losing land to protect future life. This study assesses the QOL of landless peasants in the YRD region, analyzes gender differences, and explores health inequity. The major findings are as follows.

(1) This study uses the WHOQOL-BREF scale to measure the QOL of landless peasants. We use Analysis of Variance and Nonparametric Tests to test whether the difference of mean value of testing generals have statistical significances. the results shows significant differences occur between the impacts of different genders on the four domains of QOL (physical health, psychological health, social relationships, and environment). The use of Cronbach's $\alpha$ coefficients indicates that the internal reliability of the scale is good, and the four domains of QOL are closely connected.

(2) Under the 100-score scale, scores in the four domains of QOL are relatively low, and those of females are much lower than those of males. Females generally obtain a lower QOL than males. Thus, Hypothesis 1 is supported.

Table 10 Path coefficients of each domain on the QOL of landless male peasants

\begin{tabular}{lcccc}
\hline & Estimate & S.E. & C.R. & $P$ \\
\hline Physical health $<--$-QOL & 1.000 & & & \\
Psychological health $<--$-QOL & 1.254 & .102 & 12.037 & $* * *$ \\
Social relationships $<--$-QOL & 1.230 & .100 & 12.600 & $* * *$ \\
Environment $<--$-QOL & 1.205 & .101 & 11.972 & $* * *$ \\
\hline $\begin{array}{l}\text { Note: ***indicates the path coefficients are significant when their confidence } \\
\text { interval is over 99\%. }\end{array}$
\end{tabular}

Table 11 Path coefficients of each domain on the QOL of landless female peasants

\begin{tabular}{lcccc}
\hline & Estimate & S.E. & C.R. & $\boldsymbol{P}$ \\
\hline Physical health $<--$-QOL & 1.000 & & & \\
Psychological health $<--$-QOL & 1.177 & .150 & 7.870 & $*^{* *}$ \\
Social relationships $<--$-QOL & 1.098 & .141 & 7.766 & $* * *$ \\
Environment $<--$-QOL & 1.057 & .142 & 7.463 & $* * *$ \\
\hline
\end{tabular}

Note: ***indicates the path coefficients are significant when the confidence interval is over $99 \%$.

(3) Results of the CFA analysis on each QOL domain and its related observed variables indicate good model fit, and the observed variables reflect each QOL domain.

(4) Estimation on the path coefficients of the gender differences analysis based on CFA shows that when others remain unchanged, scores in physical health increase with 1, and the QOL of both males and females increases with 1; when scores in psychological health increase with 1, the QOL of males and females increases with 1.254 and 1.177, respectively; scores in social relationships increase with 1, and the QOL of males and females increases with 1.230 and 1.098, respectively; and when scores in environment increase with 1, the QOL of males and females increases with 1.205 and 1.057, respectively. Each domain shows less impact on the QOL of females than males. Thus, Hypothesis 2 is supported.

First, the QOL of females is significantly and commonly worse than that of males. This result is partly consistent with previous studies. Health inequity in genders has been a long-term phenomenon in rural China $[46,47]$. Several indicators (education, income, and occupation) associated with health imply that females are more disadvantaged than males. In traditional villages, the man, as the headmaster of a family, takes on a physically demanding job. His income may provide the greatest support for the entire family. Thus, he has to deal with more pressure. Meanwhile, women are engaged in less physically demanding work. After the birth of their children, women are more likely to give up jobs and choose to become housewives at home. Thus, women face relatively less pressure compared with men. Moreover, previous studies have reported that men are more likely to smoke than women in rural and urban China [60-62]; the former are likewise more likely to drink

Table 12 Proportions of path coefficients in gender difference

\begin{tabular}{lcccc}
\hline & $\begin{array}{c}\text { Physical } \\
\text { health }\end{array}$ & $\begin{array}{c}\text { Psychological } \\
\text { health }\end{array}$ & $\begin{array}{c}\text { Social } \\
\text { relationships }\end{array}$ & Environment \\
\hline QOL (male) & $21.33 \%$ & $26.74 \%$ & $26.23 \%$ & $25.70 \%$ \\
QOL (female) & $23.08 \%$ & $27.17 \%$ & $25.35 \%$ & $24.40 \%$ \\
\hline
\end{tabular}


alcohol than the latter [62,63]. Excessive smoking or drinking is considered unhealthy.

Second, the four domains show different impacts on the QOL of landless male and female peasants. Psychological health shows the greatest impact on the QOL of females. Several reasons may explain the lower QOL scores that females obtain.

1) Landless female peasants have a weaker sense of security. They live under unsatisfactory living conditions, are hampered by traffic conditions, suffer from inadequate health services, and have limited information from their external environment. Women require more from their living environment because a comfortable living environment contributes to a healthy life. When women lose land, their sense of security sharply decreases and their living environment becomes unsatisfactory, consequently negatively affecting their QOL. With regard to traffic, its unfavorable conditions (i.e., inconvenience, overcrowding) cause women, whether those stranded in villages or hovering at the edge of city, difficulty in going about their daily lives with comfort and ease. Moreover, most women require health services for gynecological diseases, pregnancy, and other conditions. However, when a realistic health environment does not fulfill the requirements, the QOL of landless female peasants is considerably reduced.

2) Women living in urban villages in China are less likely to communicate with others or obtain substantial help from their friends. Migration has brought changes in women's reproductive behavior [64]. These women are likewise dissatisfied with their sexual lives. Social relationships include relationships with families, friends, workmates, and so on. Their relationships with families have two aspects. On the one hand, their husbands ought to have off-farm work because they have lost land. This situation reduces communication with their husbands, which adversely affects the quality of their social relationships. On the other hand, their sexual lives are diminished or become unsatisfactory due to the unfavorable living environment and the absence of husbands. Their fundamental physical needs are not fulfilled, thus decreasing their QOL.

3) "High mobility among rural-to-urban migrants is associated with increased sexual risk" [65]. A study further pointed out that both migrants and nonmigrants are at risk of HIV infection; thus, intervention programs that aim to reduce sexual risk behaviors should cover both groups in rural China [66]. And the utilization of medical services helps to improve health [67]. With regard to relationships with friends of the same age, they provide insufficient help. Female friends cannot offer valid help because they are limited by their ability. Male friends provide less help in traditional villages. As for relationships with colleagues, many women do not have jobs. Thus, considering that women require more daily communication than men, poor social relationships have worsened the QOL of landless female peasants.

4) Women are doubtful about their capacity to carry out their daily activities and their working ability itself. They likewise lack adequate sleep, which depletes their energy. Although the rural labor market development in China has improved the welfare of women, women have not achieved parity with men [68]. Landless female peasants, regardless of their identity as "female" or "peasants," always suffer from gender or employment discrimination, which significantly affects their psychological health. Their efforts are always ignored and seldom recognized. They tend to easily lose their self-esteem and their passion for life. Physical and psychological health influence and complement each other. Under depressing and burdensome conditions, landless female peasants experience a decline in their quality of sleep, which reduces their energy, ultimately trapping them in the vicious cycle of declining physical and psychological health.

5) Women may find life meaningless, lack enjoyment in life, and lose their daily concentration.

Subjectively, the third point highlights the important impact of psychological health on physical health; hence, women lacking in physical passion tend to have a poor mental status. Objectively, the lack of recreational activities resulting from the backward economy and incomplete infrastructure in rural China causes boredom and physical deterioration. And phenomenon of "empty-nest" is common in rural China, which negatively affects the HQOL [69]. Moreover, as they used to be engaged in agricultural activities, a working environment of "facing the loess and backing the sky" has put women in poor shape. Their lack of awareness of fashion and self-care as well as rare consideration for ways to overcome their poor shape produces strong negative emotions [70].

The peasants' loss of land is an inevitable phenomenon in economic and social development and urbanization. Landless peasants have lost natural resources to support their livelihood. When local governments pursue economic development and focus on their own performance, they sacrifice the interests of peasants in the process of land acquisition, compensation, and resettlement, causing a range of adverse social consequences. 
But the assistance policies of governments can help to improve the QOL $[71,72]$. The results in this study are alarming. The QOL of landless peasants is relatively poor, and that of female peasants is even poorer. Government intervention is thus urgently required.

We suggest several recommendations. First, the government should improve the living conditions of landless peasants, including those concerning traffic, recreation, and other infrastructure, as well as beautify the surrounding environment. Second, the government should promote the social relationships of landless peasants by providing training lessons on occupational knowledge and skills, creating a good atmosphere for communication, and facilitating their inclusion in urban society. Third, with regard to improving the physical and psychological health of landless peasants, the government should increase the number of health care facilities and size of the personnel, and promote health knowledge to increase their awareness of disease prevention.

This study has several limitations. First, the study derived samples in relatively developed cities. However, the development of the YRD region is not completely balanced, and some cities are backward. These cities are undergoing rapid urbanization, and many peasants are landless. Future research may expand its scope by examining a larger scale of the YRD region. Second, this study only considers the gender differences in the QOL of Chinese landless peasants. Future research may explore the associations between QOL and demographic characteristics (e.g. age and education.) Third, landless peasants are a large, vulnerable group in China; thus, long-term concern for their QOL should be emphasized to address health inequity and adjust the policies and efforts of governments.

\section{Conclusion}

Urbanization has accelerated in China, and large amounts of arable land have been transformed into urban land. Moreover, the number of landless peasants has continually increased. Peasants lose not only their land, but also a series of rights and interests related with land. Problems of landless peasants have been long-standing; however, only a few studies have examined their health or QOL. Based on these reality needs and to fill the gap in the literature, we use the WHOQOL-BREF scale to perform an analysis and modeling. In this manner, we assess the QOL of landless peasants in the YRD region, analyze gender differences, and explore health inequity. The major findings are as follows.

First, the scores in each QOL domain are commonly low, whereas the scores of females are much lower, indicating a poorer QOL than that of males. The scores reveal the pessimistic QOL condition of landless female peasants, whose problems are more significant than those of land male peasants. To solve these problems, more social attention and support should be provided to this vulnerable group. Moreover, appropriate and reasonable intervention should be provided in a timely fashion to help them achieve normal QOL conditions.

Second, the order of importance of four domains affecting QOL from high to low (psychological health, social relationships, environment, and physical health) is the same for landless male and female peasants, whereas the proportion of importance is different between genders.

The results of this study highlight the importance of government intervention to improve the QOL of Chinese landless peasants to reduce health inequity. Reducing health inequity between genders requires the promotion of social concern for Chinese landless female peasants. Thus, the government should provide a timely, appropriate, and reasonable intervention to help landless peasants achieve normal QOL conditions.

\section{Competing interests}

The authors declare that they have no competing interests.

\section{Authors' contributions}

$Y L$ wrote and revised the manuscript, was responsible for the design of the study, and performed the statistical analysis. SL participated in the design of the study and in the statistical analysis. Both authors read and approved the final manuscript.

\section{Acknowledgments}

This paper is supported by the General Program of National Natural Science Foundation of China (No. 71173099), the Youth Program of National Natural Science Foundation of China (No. 70903002) and the Program for New

Century Excellent Talents in University (No. NCET-11-0228).

The authors also want to thank Peiyi Lu (Sun Yat-sen University) and Wanyi Lu (Nanjing University) for their contributions to this study.

\section{Author details}

${ }^{1}$ Department of Social Work and Social Policy, School of Social and Behavioral Sciences, Nanjing University, Nanjing 210023, Jiangsu province, People's Republic of China. ${ }^{2}$ School of Social and Behavioral Sciences, Nanjing University, Nanjing 210023, People's Republic of China.

Received: 29 January 2014 Accepted: 8 May 2014

Published: 15 May 2014

\section{References}

1. Research Group in Ministry of Labor and Security: A research on the social security system on landless farmers in China. China Labor 2007, 2:10-14.

2. Zhang YD: A retrospect of the research for China's lost-land peasants of the 10 years. J Shanghai Univ (Social Sciences) 2010, 17(5):27-35.

3. Tan MH, Li XB, Xie H, Lu CH: Urban land expansion and arable land loss in China-a case study of Beijing-Tianjin-Hebei region. Land Use Policy 2005, 22:187-196

4. Tan R, Qu FT, Heerink N, Mettepenningen E: Rural to urban land conversion in China-How large is the over-conversion and what are its welfare implications? China Econ Rev 2011, 22:474-484.

5. Deng XZ, Huang JK, Rozelle S, Uchida E: Growth, population and industrialization, and urban land expansion in China. J Urban Econ 2008, 63:96-115.

6. He SJ, Liu YT, Webster C, Wu FL: Property rights redistribution, entitlement failure and impoverishment of landless farmers in China. Urban Stud 2009, 46(9):1925-1949.

7. Ding CR: Policy and praxis of land acquisition in China. Land Use Policy 2007, 24:1-13. 
8. Hui ECM, Bao HJ, Zhang XL: The policy and praxis of compensation for land expropriations in China: an appraisal from the perspective of social exclusion. Land Use Policy 2013, 32:309-316.

9. Guo XL: Research on the society security of the landless peasants of Henan Province. Business, Economics, Finical Sciences, and Management. Berlin Heidelberg: Springer; 2012:69-74. 143.

10. Liang $Y, L u W, W u W$ : Are social security policies for Chinese landless farmers really effective on health in the process of Chine se rapid urbanization? a study on the effect of social security policies for Chinese landless farmers on their health-r elated quality of life. Int J Equity Health 2014, 13:5.

11. Zhang $H$, Tong $X$ : Self-identity of the passive-urbanized group in the process of obtaining urban adaptability and modernity: an empirical study on 561 land-displaced peasants in Nanjing. Sociol Stud 2006, 2:86-106.

12. Wang $H$, Kindig DA, Mullahy J: Variation in Chinese population health related quality of life: results from a EuroQol study in Beijing, China. Qual Life Res 2005, 14:119-132.

13. Wang HM, Patrick DL, Edwards TC, Skalicky AM, Zeng HY, Gu WW: Validation of the EQ-5D in a general population sample in urban China. Qual Life Res 2012, 21(1):155-160.

14. Sun $S$, Chen J, Johannesson $M$, Kind $P, X u$ L, Zhang $Y$, Burström K: Population health status in China: EQ-5D results, by age, sex and socio-economic status, from the National Health Services Survey 2008. Qual Life Res 2011, 20:309-320.

15. Skevington SM: Advancing cross-cultural research on quality of life: Observations drawn the WHOQOL development. Qual Life Res 2002, 11:135-144.

16. Power $M$, Bullinger $M$, Harper $A$ : The World Health Organization WHoQOL100: Tests of the universality of quality of life in 15 different cultural groups worldwide. Health Psychol 1999, 18(5):495-505.

17. Cruz LN, Polanczyk CA, Camey SA, Hoffmann JF, Fleck MP: Quality of life in Brazil: normative values for the Whoqol-bref in a southern general population sample. Qual Life Res 2011, 20(7):1123-1129.

18. World Health Organization, Division of Mental Health: WHOQOL-BREF: Introduction, Administration, Scoring and Generic Version of the Assessment: Field Trial Version, December 1996. Geneva: World Health Organization; 1996.

19. Skevington SM, Sartorius N, Amir M: Developing methods for assessing quality of life in different cultural settings. Soc Psychiatry Psychiatr Epidemio/ 2004, 39(1):1-8

20. Harper A, Power M, on behalf of the WHOQOL Group: Development of the World Health Organization WHOQOL-BREF Quality of Life Assessment. Psychol Med 1998, 28:551-558.

21. Noerholm V, Groenvold M, Watt T, Bjorner JB, Rasmussen NA, Bech P: Quality of life in the Danish general population-normative data and validity of WHOQOL-BREF using Rasch and item response theory models. Qual Life Res 2004, 13(2):531-540.

22. Nedjat S, Naieni KH, Mohammad K, Majdzadeh R, Montazer A: Quality of life among an Iranian general population sample using the World Health Organization's quality of life instrument (WHOQOL-BREF). Int J Public Health 2011, 56(1):55-61.

23. Min SK, Lee Cl, Kim Kl, Jung YC, Suh SY: Development of Korean version of WHO quality of life scale abbreviated version (WHOQOL-BREF). J Korean Neuropsychiatr Assoc 2000, 39(3):571-579.

24. Yao G, Chung CW, Yu CF, Wang JD: Development and verification of validity and reliability of the WHOQOL-BREF Taiwan version. J Formos Med Assoc 2002, 101(5):342-351.

25. Leung KF, Wong WW, Tay MSM, Chu MML, Ng SSW: Development and validation of the interview version of the Hong Kong Chinese WHOQOLBREF. Qual Life Res 2005, 14(5):1413-1419.

26. Skevington SM, Lotfy M, O'Connell KA: The World Health Organization's WHOQOL-BREF assessment: Psychometric properties and results of the international field trial a report from the WHOQOL Group. Qual Life Res 2004, 13:299-310.

27. Hao Y, Fang J: The introduce and usage of WHOQOL instrument in Chinese. Mod Rehabil 2000, 4(8):1127-1129.

28. Xia P, Li NX, Hau KT, Liu C, Lu Y: Quality of life of Chinese urban community residents: a psychometric study of the mainland Chinese version of the WHOQOL-BREF. BMC Med Res Methodol 2012, 12:37-47.

29. Chan SWC, Shoumei JIA, Thompson DR, Yan HU, Chiu HFK, Chien W, Lam L: A cross-sectional study on the health related quality of life of depressed Chinese older people in Shanghai. Int J Geriatr Psychiatry 2006, 21:883-889.
30. Zhang JT, Li XM, Fang XY, Xiong Q: Discrimination experience and quality of life among rural-to-urban migrants in China: the mediation effect of expectation-reality discrepancy. Qual Life Res 2009, 18:291-300.

31. Wang B, Li XM, Stanton B, Fang XY: The influence of social stigma and discriminatory experience on psychological distress and quality of life among rural-to-urban migrants in China. Soc Sci Med 2010, 71:84-92.

32. Li LJ, Young D, Xiao SY, Zhou X, Zhou L: Psychometric properties of the WHO quality of life questionnaire (WHOQOL-100) in patients with chronic diseases and their caregivers in China. Bull World Health Organ 2004, 82(7):493-502.

33. Wang XD, Gao L, Zhang H, Zhao C, Shen Y, Shinfuku N: Post-earthquake quality of life and psychological well-being: Longitudinal evaluation in a rural community sample in northern China. Psychiatry Clin Neurosci 2000, 54:427-433.

34. Xu T, Wu ZY, Rou KM, Duan S, Wang HS: Quality of life of children living in HIV/AIDS-affected families in rural areas in Yunnan, China. AIDS Care 2010, 22(3):390-396.

35. Zhou B, Chen K, Wang J, Wang H, Zhang S, Zheng W: Quality of life and related factors in the older rural and urban Chinese populations in Zhejiang Province. J App/ Gerontol 2011, 30(2):199-225.

36. Moss NE: Gender equity and socioeconomic inequality: a framework for the patterning of women's health. Soc Sci Med 2002, 54(5):649-661.

37. Sen G, Östlin P: Gender inequity in health: why it exists and how we can change it. Glob Public Health 2008, 3(S1):1-12.

38. Clarke AE, Olesen V: Revisioning Women, Health and Healing: Feminist, Cultural and Technoscience Perspective. East Sussex: Psychology Press; 2013.

39. Liang Y, Cao R: Is the health status of female victims poorer than males in the post-disaster reconstruction in China: a comparative study of data on male victims in the first survey and double tracking survey data. BMC Womens Health 2014, 14(1):18.

40. Liang $Y$, Chu $P$, Wang $X$ : Health-related quality of life of Chinese earthquake survivors: a case study of five hard-hit disaster counties in Sichuan. Soc Indic Res 2013: 1-24. doi:10.1007/s11205-013-0525-2.

41. Norris CM, Ghali WA, Galbraith PD, Graham MM, Jensen LA, Knudtson ML, the APPROACH Investigators: Women with coronary artery disease report worse health-related quality of life outcomes compared to men. Health Qual Life Outcomes 2004, 2(1):21.

42. Vázquez I, Valderrábano F, Fort I, Jofré R, López-Gómez JM, Moreno F, Sanz-Guajardo D, Groupo Cooperativo Español para el estudio de la Calidad de Vida del paciente renal de la Sociedad Española de Nefrología: Differences in health-related quality of life between male and female hemodialysis patients. Nefrologia 2003, 24(2):167-178.

43. Bisegger C, Cloetta B, von Bisegger U, Abel T, Ravens-Sieberer U: Healthrelated quality of life: gender differences in childhood and adolescence. Soz Praventivmed 2005, 50(5):281-291.

44. Tajvar M, Arab M, Montazeri A: Determinants of health-related quality of life in elderly in Tehran, Iran. BMC Public Health 2008, 8(1):323.

45. Hu Y: Disease burdens, structural challenges and policy options: rural Chinese women's health under the landscape of globalization. Popul Dev 2008, 14(2):54-68.

46. Yu MY, Sarri R: Women's health status and gender inequality in China. Soc Sci Med 1997, 45(12):1885-1898.

47. Anson O, Sun SF: Gender and health in rural China: evidence from HeBei province. Soc Sci Med 2002, 55:1039-1054.

48. Wang JM, Fei Y, Shen HB, Xu B: Gender difference in knowledge of tuberculosis and associated health-care seeking behaviors: a cross-sectional study in a rural area of China. BMC Public Health 2008, 8:354-360.

49. Anson O, Sun SF: Health inequalities in rural China: evidence from HeBei Province. Health Place 2004, 10:75-84.

50. Li DK, Tsang MC: Household decisions and gender inequality in education in rural China. China Int J 2003, 1(2):224-246.

51. Hannum E: Poverty and basic education in rural China: Villages, households, and girls' and boys' enrollment. Comp Educ Rev 2003, 47(2):141-159.

52. Hannum E, Kong P, Zhang YP: Family sources of educational gender inequality in rural China: a critical assessment. Int J Educ Dev 2009, 29:474-486.

53. Song $L$, Appleton S, Knight J: Why do girls in rural China have lower school enrollment. World Dev 2006, 34(9):1639-1653.

54. Wu J, Li Y, Rao KQ, Sun Q, Qian J, Li Z: Education-related gender differences in health in rural China. Am J Public Health 2004, 94:1713-1716. 
55. Mattews R: Gender inequality and economic growth in rural China. Soc Sci Res 2000, 29:606-632.

56. National Bureau of Statistics of China: China Statistical Yearbook of 2012. Beijing: China Statistics Press; 2013.

57. Cao Y, Chen J, Cao JW, Qian JC: Application of Kish Grid sampling in world health survey (China survey). Fudan Univ J Med Sci 2004, 31(3):307-310

58. Hsiung PC, Fang CT, Chang YY, Chen MY, Wang JD: Comparison of WHOQOL-BREF and SF-36 in patients with HIV infection. Qual Life Res 2005, 14(1):141-150.

59. Huang IC, WU AW, Frangakis C: Do the SF-36 and WHOQOL-BREF measure the same constructs? Evidence from the Taiwan population. Qual Life Res 2006, 15(1):15-24

60. Yang G, Fan L, Tan J, Qi G, Zhang Y, Samet JM, Taylor CE, Becker K, Xu J: Smoking in China: findings of the 1996 national prevalence survey. J Am Med Assoc 1999, 282(13):1247-1253.

61. Chen XG, Li XM, Stanton B, Qi G, Zhang Y, Samet JM, Taylor CE, Becker K $\mathrm{Xu}$ J: Cigarette smoking among rural-to-urban migrants in Beijing, China. Prev Med 2004, 39:666-673.

62. Shi J, Liu M, Zhang Q, Lu M, Quan H: Male and female adult population health status in China: a cross-sectional national survey. BMC Public Health 2008, 8:277-285.

63. Wu B, Mao ZF, Rockett I, Yue YW: Socioeconomic status and alcoholic use among urban and rural residents in China. Subst Use Misuse 2008, 43:952-966.

64. Liang Y, Yi Y, Sun Q: The impact of migration on fertility under China's underlying restrictions: a comparative study between permanent and temporary migrants. Soc Indic Res 2014, 116:307-326.

65. Li X, Stanton B, Fang X, Lin D, Mao R, Wang J, Cottrell L, Harris C: HIV/Std risk behaviors and perceptions among rural-to-urban migrants in China. AIDS Educ Preview 2004, 16(6):538-556.

66. Hu Z, Liu H, Li X, Stanton B, Chen X: HIV-related sexual behavior among migrants and non-migrants in a rural area of China: Role of rural-to-urban migration. Public Health 2006, 120:339-345.

67. Liang Y, Guo M: Utilization of health services and health-related quality of life research of rural-to-urban migrants in China: a cross-sectional analysis. Soc Indic Res 2014, 1-19. doi:10.1007/s11205-014-0585-y.

68. Zhang LX, Brauw AD, Rozelle S: China's rural labor market development and its gender implications. China Econ Rev 2004, 15:230-247.

69. Liang Y, Wu W: Exploratory analysis of health-related quality of life among the empty-nest elderly in rural China: An empirical study in three economically developed cities in eastern China. Health Qual Life Outcomes 2014, 12(1):59.

70. Tiggemann M, McGill, B: The role of social comparison in the effect of magazine advertisements on women's mood and body dissatisfaction. Journal of Social and Clinical Psychology 2004, 23(1):23-44

71. Liang Y, Cao R: Employment assistance policies of Chinese government play positive roles! The impact of post-earthquake employment assistance policies on the health-related quality of life of Chinese earthquake populations. Soc Indic Res 2014, 1-23. doi:10.1007/s11205-014-0620-z.

72. Liang $Y$, Wang $X$ : Developing a new perspective to study the health of survivors of Sichuan earthquakes in China: a study on the effect of postearthquake rescue policies on survivors' health-related quality of life. Health Res Policy Syst 2013, 11(1):41.

doi:10.1186/1477-7525-12-71

Cite this article as: Liang and Li: Landless female peasants living in resettlement residential areas in China have poorer quality of life than males: results from a household study in the Yangtze River Delta region. Health and Quality of Life Outcomes 2014 12:71.

\section{Submit your next manuscript to BioMed Central and take full advantage of:}

- Convenient online submission

- Thorough peer review

- No space constraints or color figure charges

- Immediate publication on acceptance

- Inclusion in PubMed, CAS, Scopus and Google Scholar

- Research which is freely available for redistribution 